(C) 2022, The Authors. Published by Elsevier Inc. and Fass Inc. on behalf of the American Dairy Science Association ${ }^{\circledR}$. This is an open access article under the CC BY license (http://creativecommons.org/licenses/by/4.0/).

\title{
Are subjectively scored linear type traits suitable predictors of the genetic merit for feed intake in grazing Holstein-Friesian dairy cows?
}

\author{
M. Williams, ${ }^{1,2} \odot$ C. P. Murphy, ${ }^{2} \odot$ R. D. Sleator, ${ }^{2} \odot$ S. C. Ring, ${ }^{3} \oplus$ and D. P. Berry ${ }^{1 *} \oplus$ \\ ${ }^{1}$ Department of Animal Bioscience, Animal and Grassland Research and Innovation Centre, Teagasc, Moorepark, Fermoy, Co. Cork, \\ Ireland P61 C996 \\ ${ }^{2}$ Department of Biological Sciences, Munster Technological University, Bishopstown, Co. Cork, Ireland T12 P928 \\ ${ }^{3}$ Irish Cattle Breeding Federation, Highfield House, Bandon, Co. Cork, Ireland P72 X050
}

\begin{abstract}
Measuring dry matter intake (DMI) in grazing dairy cows using currently available techniques is invasive, time consuming, and expensive. An alternative to directly measuring DMI for use in genetic evaluations is to identify a set of readily available animal features that can be used in a multitrait genetic evaluation for DMI. The objectives of the present study were thus to estimate the genetic correlations between readily available body-related linear type traits and DMI in grazing lactating Holstein-Friesian cows, but importantly also estimate the partial genetic correlations between these linear traits and DMI, after adjusting for differences in genetic merit for body weight. Also of interest was whether the predictive ability derived from the estimated genetic correlations materialized upon validation. After edits, a total of 8,055 test-day records of DMI, body weight, and milk yield from 1,331 HolsteinFriesian cows were available, as were chest width, body depth, and stature from 47,141 first lactation HolsteinFriesian cows. In addition to considering the routinely recorded linear type traits individually, novel composite traits were defined as the product of the linear type traits as an approximation of rumen volume. All linear type traits were moderately heritable, with heritability estimates ranging from 0.27 (standard error $=0.14$ ) to 0.49 (standard error $=0.15$ ); furthermore, all linear type traits were genetically correlated ( 0.29 to 0.63 , standard error 0.14 to 0.12 ) with DMI. The genetic correlations between the individual linear type traits and DMI, when adjusted for genetic differences in body weight, varied from -0.51 (stature) to 0.48 (chest width). These genetic correlations between DMI and linear type traits suggest linear type traits may be useful predictors of DMI, even when body weight informa-
\end{abstract}

Received June 25, 2021.

Accepted October 18, 2021.

*Corresponding author: donagh.berry@teagasc.ie tion is available. Nonetheless, estimated genetic merit of DMI derived from a multitrait genetic evaluation of linear type traits did not correlate strongly with actual DMI in a set of validation animals; the benefit was even less if body weight data were also available.

Key words: dry matter intake, genetic evaluation, heritability, selection index

\section{INTRODUCTION}

Dairy breeding programs have contributed considerably to observed gains in a range of traits, including milk yield and fertility (Berry et al., 2014; Berry et al., 2016; García-Ruiz et al., 2016). Nonetheless, interest in improving production efficiency is intensifying, with a growing emphasis on feed and environmental efficiency (Pryce et al., 2014; Hurley et al., 2017). The heritability of feed intake in dairy cows is widely reported to be between 0.07 and 0.44 , with documented exploitable genetic differences in feed intake (Veerkamp and Brotherstone, 1997; Berry et al., 2007; Toshniwal et al., 2008). Despite this abundance of genetic variability, the direct inclusion of feed intake and efficiency into dairy breeding goals has been slow. Australia and the United States currently explicitly consider a feed intake-related measure (i.e., feed saved) in their dairy breeding objectives (Pryce et al., 2015; Byrne et al., 2016; CDCB, 2020, 2021), albeit their genetic evaluations are based on actual feed intake measured in limited populations of 2,036 and 6,200 individuals, respectively. Considering this, novel strategies to include feed intake in dairy cow breeding goals should be thoroughly investigated.

The main barrier, at present, to incorporating feed intake into a breeding program is the lack of an easy, cost-effective approach to measuring DMI, which could be used to routinely determine individual cow feed intake. This is particularly true for feed intake in grazing dairy cows, where the currently recommended marker techniques for estimating feed intake in grazing systems (e.g., the n-alkane technique; Mayes et al., 1986) have 
proven both complex and expensive. There is, therefore, an urgent requirement to identify indicators of feed intake, especially at a genetic level, for incorporation into dairy cow genetic evaluations. Ideally, data collection for these indicator traits would be incorporated into routine management practices, or at least be measurable at low cost in a large population of cattle. Various indicator measurements of feed intake and feed efficiency in dairy cows have been previously suggested, including milk yield, BW, grazing and ruminating behavior, fecal near-infrared reflectance spectroscopy, and mid-infrared reflectance spectroscopy of milk (Halachmi et al., 2004; Tran et al., 2010; McParland et al., 2014; Halachmi et al., 2016).

Linear type traits are a subjective visual assessment of the biological extremes of biometric characteristics; they are heritable and are routinely recorded on breeding dairy cows (Veerkamp and Brotherstone, 1997; Berry et al., 2004; Manafiazar et al., 2016). Although previous studies in dairy cows have reported genetic associations between linear type traits and feed intake (Veerkamp and Brotherstone, 1997; Manafiazar et al., 2016; Manzanilla-Pech et al., 2016), they have been exclusive to confined dairy cows (Veerkamp and Brotherstone, 1997; Manafiazar et al., 2016; Manzanilla-Pech et al., 2016). To date, no study has, to the best of our knowledge, quantified the marginal information content of the linear type trait in predicting genetic merit for DMI, over and above that predictable from just BW data. The use of BW records as a predictor of feed intake is of particular interest given the likely uptake of automated weighing in the future (Alawneh et al., 2011; Song et al., 2018). Moreover, validation of the prediction of genetic merit from correlated linear type traits has never been undertaken using actual phenotypic data from a validation population. Furthermore, the effectiveness of linear type traits as suitable indicators of feed intake has, to the best of our knowledge, never been investigated in pasture-fed dairy cows. It cannot be assumed that the genetic correlations with feed intake will be similar to those documented from indoor systems, especially given that the genetic correlations between feed intake in grazing versus high input systems are reported to be weak to moderate $(0.14$ to 0.33; Berry et al., 2014). The greater gut fill associated with grazed grass (Gill et al., 1988) may imply that rumen capacity could likely limit potential feed intake in grazing systems. Therefore, the objective of the present study was to estimate the genetic correlations between readily available body-related linear type trait information and DMI in grazing lactating dairy cows. Of particular interest was the partial genetic correlation between these linear traits and DMI after adjusting for either phenotypic or genetic differences in BW. Also of interest was whether the expected predictive ability for DMI derived from a multitrait genetic evaluation with the linear score materialized in a validation population.

\section{MATERIALS AND METHODS}

\section{DMI Data}

Records relating to individual cow daily grass DMI estimates, concentrate DMI, BW, and milk yield, collected between the years 1995 and 2019, inclusive, were available from the Animal and Grassland Research and Innovation Centre, Teagasc Moorepark, Co. Cork, Ireland. Feed intake data were collected as part of $>25$ experiments, which evaluated alternative grazing and nutritional strategies or strain of Holstein-Friesian cows on 6 Teagasc research farms. All animals were managed under a rotational grazing system and grazed predominantly on perennial ryegrass swards. All animals grazed freely with continuous access to water and each cow received between 0 and $6.2 \mathrm{~kg}$ of concentrate DMI per day in the milking parlor. Grass DMI was estimated for all animals using the n-alkane technique described by Mayes et al. (1986), and modified by Dillon and Stakelum (1989). In brief, to estimate one daily grass DMI for an individual cow, each cow was dosed twice daily with dotriacontane for $12 \mathrm{~d}$, whereas fecal and forage samples were collected twice daily for $6 \mathrm{~d}$ from the seventh day of dosing; the n-alkane technique was repeated an average of 6 times per cow (ranging from 1 to 23 times). Dry matter intake was calculated as grass DMI plus concentrate DMI. Individual cow milk yield was recorded daily using electronic milk meters (Dairymaster). Cow live weight was recorded every 1 to $3 \mathrm{wk}$ using an electronic weighing scale (Tru-Test Limited).

Before edits, 8,267 DMI records were available from 2,605 lactations on 1,384 Holstein-Friesian cows. Individual DMI and BW records were discarded if they were greater than 3 standard deviations from the population mean. Only the BW measurements recorded closest to each of the DMI measurements were retained for further analyses; $96 \%$ of BW measurements were recorded within $14 \mathrm{~d}$ of the DMI measurement. Records from cows without a known sire were removed and parity was categorized as 1,2 , or $\geq 3$; there were 746,702 , and 652 cows with DMI measurements in first, second, and third parity or higher, respectively. After edits, 8,055 DMI, BW, and milk yield records remained from 2,525 lactations on 1,331 cows. Days in milk (ranging from 5 to 280 DIM) were categorized into 30 -d intervals, and for use in a separate analysis, 3 stages of lactation were also defined (i.e., early, mid, and late); 2,789 records 
were classified as early lactation ( $\leq 90$ DIM), 3,205 records were classified as mid lactation (91-180 DIM), and 2,061 records were classified as late lactation $(\geq 181$ DIM). Contemporary group for DMI, BW, and daily milk yield was defined as experimental treatment by date of measurement; after edits, there were 854 contemporary groups for DMI and daily milk yield with 1,156 contemporary groups for BW.

\section{Linear Type Trait Data}

Linear type traits recorded by the Irish HolsteinFriesian Association were available from the Irish Cattle Breeding Federation national database. Records pertaining to 19 linear type traits recorded on 197,627 registered Holstein-Friesian cows during first lactation were available. Of the linear type traits records, chest width (CW), body depth (BD), and stature (STA) were retained for analyses in the present study. Each of the retained traits were scored on a scale of 1 to 9 ; $\mathrm{CW}$ was scored from narrow (i.e., score of 1 ) to wide (i.e., score of 9), BD was scored from shallow to deep, and stature was scored from short to tall. Classification of cows was performed by a single professional classifier for a given herd on a given date. Differences between classifiers were accounted for by adjusting each linear type trait by the ratio of the standard deviation of each classifier in each year to the mean standard deviation of all other classifiers for each linear type trait, as described by Brotherstone (1994). For the purposes of estimating rumen volume, in the present study, 4 novel composite traits were generated as the product of the scores of 2 or 3 linear type traits, namely $\mathrm{CW} \times \mathrm{BD}$ $($ CWBD $), \mathrm{CW} \times \mathrm{STA}($ CWSTA $), \mathrm{BD} \times \mathrm{STA}($ BDSTA), and $\mathrm{CW} \times \mathrm{BD} \times \mathrm{STA}(\mathbf{C W B D S T A})$. Adjusting for differences between classifiers transformed the linear type trait scores from a discrete scale (1 to 9 ) to a continuous scale.

Contemporary group for the linear type traits was defined as herd-date of inspection. Contemporary groups with no paternal half-sibling to a cow with DMI information were removed. All linear type trait records from cows with both DMI and BW information were also retained. Of the remaining 123,464 linear type trait records, only contemporary groups with at least 5 paternal half-siblings to cows with DMI data were retained. Subsequently, contemporary groups with $<10$ cows were discarded. Following edits, linear type trait data relating to 47,141 cows in 2,314 contemporary groups, sired by 3,428 bulls, were available for analyses. Of the 3,428 sires in the linear type trait data set, 129 also had progeny with DMI information. Of the 48,163 cows retained for analyses, 309 cows had both DMI information and linear type trait information.

\section{Statistical Analyses}

Estimation of Variance Components. Univariate animal linear mixed models in ASReml (Gilmour et al., 2008) were used to estimate the variance components for all traits. The following model was used to estimate the variance components for DMI, BW, and milk yield across the entire lactation, as well as within early, mid, and late lactation separately:

$$
\begin{aligned}
y_{i j k l m n}=C G_{j} & + \text { Parity }_{k} \times \text { DIM }_{l}+a_{i}+\text { pe } \text { within }_{m} \\
& + \text { pe } \text { across }_{n}+e_{i j k l m n}
\end{aligned}
$$

where $y_{i j k l m n}$ was the observed value of DMI, BW, or milk yield for cow $i ; C G_{j}$ was the fixed effect for contemporary group $j ;$ Parity $_{k}$ was the fixed effect of parity $k(k=1,2, \geq 3) ; D I M_{l}$ was the fixed effect for days in milk class $l(l=1$ to 10$) ; a_{i}$ was the additive random effect of cow $i$ where $a \sim N\left(0, \mathbf{A} \sigma_{a}^{2}\right)$ and $\sigma_{a}^{2}$ represents the direct genetic variance and $\mathbf{A}$ the numerator relationship matrix; the pedigree of all cows was traced back at least 4 generations; pe within $n_{m}$ was the random cow by lactation permanent environmental effect where pe within $_{m} \sim N\left(0, \mathbf{I} \sigma_{\text {pewithin }}^{2}\right)$ and $\sigma_{\text {pewithin }}^{2}$ represents the within-lactation permanent environmental variance and $\mathbf{I}$ the identity matrix; pe across $_{n}$ was the random cow permanent environmental effect where pe across $n$ $\sim N\left(0, \mathbf{I} \sigma_{\text {pe across }}^{2}\right)$ and $\sigma_{\text {peacross }}^{2}$ represents the across-lactation permanent environmental variance and I the identity matrix; and $e_{i j k l m n}$ was the residual term where $e \sim N\left(0, \mathbf{I} \sigma_{e}^{2}\right)$ and $\sigma_{e}^{2}$ represents the residual variance and $\mathbf{I}$ the identity matrix. Variance components for DMI were also estimated having adjusted phenotypically for differences in BW via its inclusion as a covariate in the mixed model. The variance components of linear type traits were estimated using the following model (Berry et al., 2004):

$$
y_{i j k l}=C G_{j}+D I M_{k}+\text { calving } \text { month }_{l}+a_{i}+e_{i j k l},
$$

where $y_{i j k l}$ was the adjusted value of the linear type trait for cow $i ; C G_{j}$ was the fixed effect of contemporary group $j ; D I M_{k}$ was the fixed effect for days in milk at the time of classification and was classified into 30-d intervals ( $k=1$ to 12 ); calving month $_{l}$ was the fixed effect for month of calving $l(l=1$ to 12$)$; $a_{i}$ was the additive random effect of cow $i$ where $a \sim N\left(0, \mathbf{A} \sigma_{a}^{2}\right)$ and $\sigma_{a}^{2}$ represents the direct genetic variance and $\mathbf{A}$ the numerator relationship matrix; and $e_{i j k l}$ is the residual term where $e \sim N\left(0, \mathbf{I} \sigma_{e}^{2}\right)$ and $\sigma_{e}^{2}$ represents the residual variance and $\mathbf{I}$ the identity matrix. 
Estimation of Genetic and Phenotypic Covariances. A series of bivariate sire linear mixed models were used to calculate the genetic and phenotypic covariances between both BW and each type trait with DMI across the entire lactation, as well as within early, mid, and late lactation separately. The genetic and phenotypic covariances among the linear type traits were estimated using a separate series of bivariate sire linear models. The fixed and random effects included in the models were those used in the univariate analyses, with the exception of a random sire term included in place of the random cow term. The partial genetic correlation between DMI and each linear type trait, adjusted for genetic differences in BW, was calculated as (Wherry, 1984)

$$
\begin{aligned}
& r_{g}\left(D M I, \text { type }_{i} \mid B W\right)= \\
& \frac{r_{g}\left(D M I, \text { type }_{i}\right)-r_{g}(D M I, B W) r_{g}\left(\text { type }_{i}, B W\right)}{\sqrt{1-r_{g}^{2}(D M I, B W)} \sqrt{1-r_{g}^{2}\left(\text { type }_{i}, B W\right)}},
\end{aligned}
$$

where $r_{g}\left(D M I\right.$, type $\left._{i}\right)$ was the genetic correlation between DMI and type trait $i ; r_{q}(D M I, B W)$ was the genetic correlation between the DMI and $\mathrm{BW} ; r_{g}\left(\right.$ type $_{i}$, $B W$ ) was the genetic correlation between the linear type trait $i$ and BW.

Genetic Evaluation. A series of multitrait animal model genetic evaluations for DMI were undertaken using the MiX99 software suite (Strandén and Lidauer, 1999) with BW or one linear type trait (or both) to validate the usefulness of linear type traits as predictor traits of genetic merit for DMI, particularly when BW information was also available. The data set from which the breeding values were estimated was the same as that used to estimate the phenotypic and genetic (co) variances. The cows with DMI and BW phenotypes from one farm (1,747 records from 246 cows) were chosen as the validation population, whereas the DMI, BW, and linear type trait records of all other cows (53,140 records from 47,917 cows) were used as the calibration data set. The fixed effects, random effects, and (co)variance components specified in the genetic evaluations were based on the results from the bivariate models used to estimate the genetic (co)variances of DMI, BW, and the linear type traits; the sire (co)variances were multiplied by 4 to convert them to animallevel (co)variances.

Separate genetic evaluations were run with different combinations of DMI, BW, and linear type traits, (i.e., including DMI only; DMI and BW; DMI and a linear type trait; DMI, BW, and a linear type trait). Each genetic evaluation was run twice, once with the DMI, $\mathrm{BW}$, and linear type trait phenotypes of validation cows masked, and once with just the DMI and linear type trait phenotypes of the validation cows masked. The accuracy of breeding values for DMI estimated using the genetic evaluations was determined by correlating the EBV of the validation cows with their respective DMI yield deviations, which were calculated using their DMI phenotypes. The DMI yield deviation values were regressed on the EBV for DMI using linear mixed models.

\section{RESULTS}

\section{Variance Components}

Descriptive statistics and heritability estimates for all traits are presented in Table 1; the heritability, genetic standard deviation, and coefficient of genetic variation of DMI itself were $0.19(\mathrm{SE}=0.036), 0.82 \mathrm{~kg}$, and 0.05 , respectively. The heritability estimates for DMI were similar when estimated from the bivariate analyses. Adjusting DMI for phenotypic differences in BW reduced the genetic standard deviation of DMI (Table 1). The heritability estimates of the linear type traits are in Table 1 and the heritability estimates for the novel composite traits of CWBD, CWSTA, BDSTA, and CWBDSTA were $0.30(\mathrm{SE}=0.015), 0.31(\mathrm{SE}$ $=0.015), 0.39(\mathrm{SE}=0.015)$, and $0.33(\mathrm{SE}=0.015)$, respectively. Descriptive statistics for DMI, BW, and daily milk yield in early mid, and late lactation are in Supplemental Table S1 (https://doi.org/10.6084/m9 .figshare.17024120.v1).

\section{Phenotypic Correlations}

Across Lactation. The phenotypic correlations between DMI measured across lactation and both the linear type traits and novel composite traits were weak $(\leq 0.04)$ with standard errors ranging from 0.05 to 0.06 (Table 2). The phenotypic correlations between BW and the linear type traits/novel composite traits ranged from $0.05(\mathrm{BD} ; \mathrm{SE}=0.026)$ to $0.17(\mathrm{STA} ; \mathrm{SE}=0.25$; Table 2). After adjusting these phenotypic correlations for phenotypic differences in BW, all linear type traits were negatively correlated with DMI (Table 2).

Within the Stages of Lactation. When DMI and BW records in early, mid, and late lactation were considered, the phenotypic correlations between DMI and all linear type traits were positive and stronger than the phenotypic correlations between DMI and linear type traits estimated across lactation. The average phenotypic correlations between BW and all linear type traits were strongest in early lactation (mean of 0.23 ) compared with mid lactation (mean of 0.13 ), late lactation (mean of 0.20; Supplemental Table S2, https://doi 
Table 1. Mean, genetic SD $\left(\sigma_{\mathrm{g}}\right)$, heritability $\left(h^{2} ; \mathrm{SE}\right.$ in parentheses), and within-lactation repeatability $(t ; \mathrm{SE}$ in parentheses) for DMI, BW, daily milk yield, and body-related linear type traits (scale 1 to 9 )

\begin{tabular}{lrrrr}
\hline Trait & Mean & \multicolumn{1}{c}{$\sigma_{\mathrm{g}}$} & $h^{2}(\mathrm{SE})$ & $t(\mathrm{SE})$ \\
\hline DMI (kg) & & & & \\
DMI $^{\mathrm{l}}$ & 16.78 & 0.82 & $0.19(0.036)$ & $0.30(0.037)$ \\
DMI Adj & 16.78 & 0.68 & $0.15(0.030)$ & $0.25(0.032)$ \\
BW (kg) & 520.89 & 32.80 & $0.56(0.057)$ & $0.69(0.054)$ \\
Daily milk yield (kg) & 21.82 & 1.55 & $0.25(0.048)$ & $0.43(0.047)$ \\
Type trait (scale: 1 to 9) & 5.3 & 0.73 & $0.27(0.015)$ & \\
Chest width & 5.7 & 0.60 & $0.27(0.014)$ & \\
Body depth & 6.7 & 0.79 & $0.49(0.015)$ & \\
Stature & & & \\
\hline
\end{tabular}

${ }^{1} \mathrm{DMI}=$ unadjusted DMI; DMI Adj $\mathrm{BW}_{\mathrm{B}}=\mathrm{DMI}$ adjusted for phenotypic differences in BW.

.org/10.6084/m9.figshare.17024456.v1), or across lactation (mean of 0.11 ; Table 2). The phenotypic correlations among the linear types are in Supplemental Table S3 (https://doi.org/10.6084/m9.figshare.17024540.v1).

\section{Genetic Correlations}

Across Lactation. The genetic correlations among the linear type traits are in Supplemental Table S3. The genetic correlations between the linear type traits and DMI measured across the entire lactation ranged from $0.29(\mathrm{SE}=0.144)$ to $0.63(\mathrm{SE}=0.122$; Table 3$)$, with the correlations between the linear type traits and $\mathrm{BW}$ measured across the entire lactation ranging from $0.47(\mathrm{SE}=0.106)$ to $0.82(\mathrm{SE}=0.056)$. Similarly, the genetic correlations between the novel composite traits and DMI measured across lactation, and the genetic correlations between the novel composite traits and BW measured across lactation were moderately to strongly positive (Table 3). Adjusting the genetic correlations between DMI and the linear type traits for phenotypic differences in BW weakened each of the genetic correlations. Adjusting for phenotypic differences in BW had the greatest effect on the genetic correlation between DMI and BDSTA, weakening the genetic correlation from $0.39(\mathrm{SE}=0.142)$ to $-0.14(\mathrm{SE}=0.166)$. Similarly, adjusting the genetic correlations between DMI measured across lactation and the linear type traits for the genetic differences in BW weakened the strength of all the genetic correlations; CW, CWBD, CWSTA, and CWBDSTA were the only linear type traits positively correlated with DMI after adjusting for the genetic differences in BW.

Within the Stages of Lactation. The genetic correlations between DMI and the linear type traits ranged from $0.14(\mathrm{SE}=0.199)$ to $0.72(\mathrm{SE}=0.147)$ in early lactation, from $0.12(\mathrm{SE}=0.179)$ to $0.43(\mathrm{SE}$ $=0.162)$ in mid lactation, and from $0.27(\mathrm{SE}=0.189)$ to $0.68(\mathrm{SE}=0.134)$ in late lactation (Table 4$)$. The genetic correlations between $\mathrm{BW}$ and the linear type traits were similar at each stage of lactation (Table 4). After adjusting for genetic differences in BW, CW was the only linear type trait positively genetically correlated with DMI in all stages of lactation. After adjusting for genetic differences in BW in early lactation, both CWSTA and CWBDSTA were the most strongly genetically correlated type traits with DMI, with respective genetic correlations of 0.90 and 0.88 . The genetic correlation between DMI and BW, and between BW and daily milk yield, was weakest in early lactation

Table 2. Phenotypic correlations (SE in parentheses) between DMI (unadjusted and adjusted for phenotypic differences in BW), BW, milk yield, and linear type traits

\begin{tabular}{|c|c|c|c|}
\hline \multirow[b]{2}{*}{ Trait } & \multicolumn{2}{|c|}{ DMI } & \multirow[b]{2}{*}{ BW } \\
\hline & $\mathrm{DMI}^{1}$ & DMI Adj $\mathrm{BW}_{\mathrm{BW}}$ & \\
\hline BW & $0.37(0.020)$ & & - \\
\hline Milk yield & $0.40(0.014)$ & $0.36(0.014)$ & $0.26(0.024)$ \\
\hline Body depth & $-0.03(0.049)$ & $-0.06(0.052)$ & $0.05(0.026)$ \\
\hline Chest width & $0.00(0.049)$ & $-0.06(0.052)$ & $0.06(0.026)$ \\
\hline Stature & $0.04(0.047)$ & $-0.03(0.049)$ & $0.17(0.025)$ \\
\hline Chest width $\times$ body depth & $0.00(0.052)$ & $-0.07(0.054)$ & $0.07(0.027)$ \\
\hline Chest width $\times$ stature & $0.02(0.052)$ & $-0.07(0.055)$ & $0.14(0.026)$ \\
\hline Body depth $\times$ stature & $0.00(0.054)$ & $-0.07(0.054)$ & $0.15(0.026)$ \\
\hline Chest width $\times$ body depth $\times$ stature & $0.01(0.055)$ & $-0.09(0.057)$ & $0.13(0.027)$ \\
\hline
\end{tabular}

${ }^{1} \mathrm{DMI}=$ unadjusted DMI; DMI Adj $\mathrm{BW}_{\mathrm{BW}}=\mathrm{DMI}$ adjusted for phenotypic differences in BW. 
(Table 4), whereas the genetic correlation between DMI and daily milk yield was strongest in early lactation (Table 4).

\section{Genetic Evaluation}

The Pearson correlation coefficients between DMI yield deviations and the EBV for DMI in the validation population are shown in Table 5 . The correlation between DMI yield deviations and the EBV for DMI of the validation cows, estimated via their relationships with the cows with just DMI phenotypes, was 0.14 (Table 5). When DMI yield deviations of the validation population were regressed on their EBV for DMI, estimated with the DMI phenotypes only, a 1-unit increase in the EBV for DMI was associated with a $0.63-\mathrm{kg}$ (SE $=0.103$ ) increase in DMI (Table 5). With the exception of STA, EBV for DMI using one linear type trait plus DMI information of the calibration population did not strengthen the correlation between DMI yield deviations and the EBV for DMI relative to generating the EBV for DMI with DMI phenotypes only. Regressing DMI yield deviations of the validation population on their EBV for DMI, generated with DMI and STA phenotypes of the calibration population, resulted in a regression coefficient of $0.65(\mathrm{SE}=0.102)$. The correlation between DMI yield deviations and the EBV for DMI strengthened by $30.6 \%$ (i.e., 0.14 to 0.19 ) when DMI and BW phenotypes of the calibration population were used to generate EBV for DMI compared with just using DMI information.

The correlation between DMI yield deviation and breeding values for DMI estimated using both the DMI phenotypes from the calibration population and all available BW phenotypes was 0.32 (Table 5). With the exception of STA, including a linear type trait, along with both DMI information from the calibration population and all available BW phenotypes, did not strengthen the correlations with DMI. Including STA records from the calibration cows, in addition to their DMI records and all BW data, strengthened the correlation between DMI yield deviation and EBV for DMI by just $0.01(1.9 \%)$ over and above not considering STA (Table 5). When the EBVs for DMI generated without any DMI information from the calibration population were compared with their respective EBVs for DMI generated with DMI information from the calibration population (e.g., comparing the EBV for DMI generated with CWBDSTA only to the EBV for DMI generated with DMI from the calibration data and CWBDSTA), the EBVs for DMI generated without any DMI information were always more weakly correlated with phenotypic DMI (Table 5).

\section{DISCUSSION}

The inclusion of feed intake in dairy cow breeding goals is currently limited by the large resource requirements associated with the capture of individual cow feed intake data (Berry and Crowley, 2013), particularly in grazing cows. Various indicator measurements for feed intake have been proposed including near-infrared reflectance spectroscopy (Tran et al., 2010; Lahart et al., 2019), mid-infrared reflectance spectroscopy of milk (McParland et al., 2014; Wallén et al., 2018), and linear type traits (Bilal et al., 2016; Manafiazar et al., 2016; Manzanilla-Pech et al., 2016). Individual cow BW are routinely recorded on some farms and therefore investigation into the utility of $\mathrm{BW}$ records in addition to other proxy traits in genetic evaluations for DMI is warranted. There is a dearth of information on the marginal predictive ability of proxy traits in predicting DMI over and above that already captured from routine BW measurements. Moreover, previous studies that proposed potential predictor traits for DMI did not actually undertake a validation of DMI EBV generated

Table 3. Genetic correlations (SE in parentheses) between DMI (unadjusted, adjusted for phenotypic or genetic differences in BW), BW, milk yield, and linear type traits

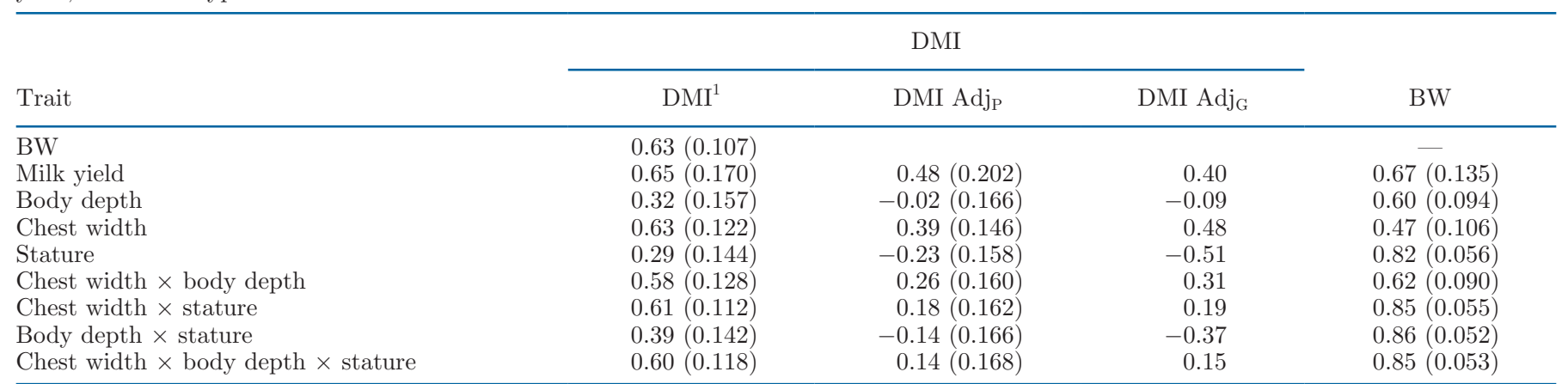

${ }^{1} \mathrm{DMI}=$ unadjusted DMI; DMI Adj $\mathrm{P}=\mathrm{DMI}$ adjusted for phenotypic differences in BW; DMI Adj $\mathrm{G}_{\mathrm{G}}=$ DMI adjusted for genetic differences in BW. 


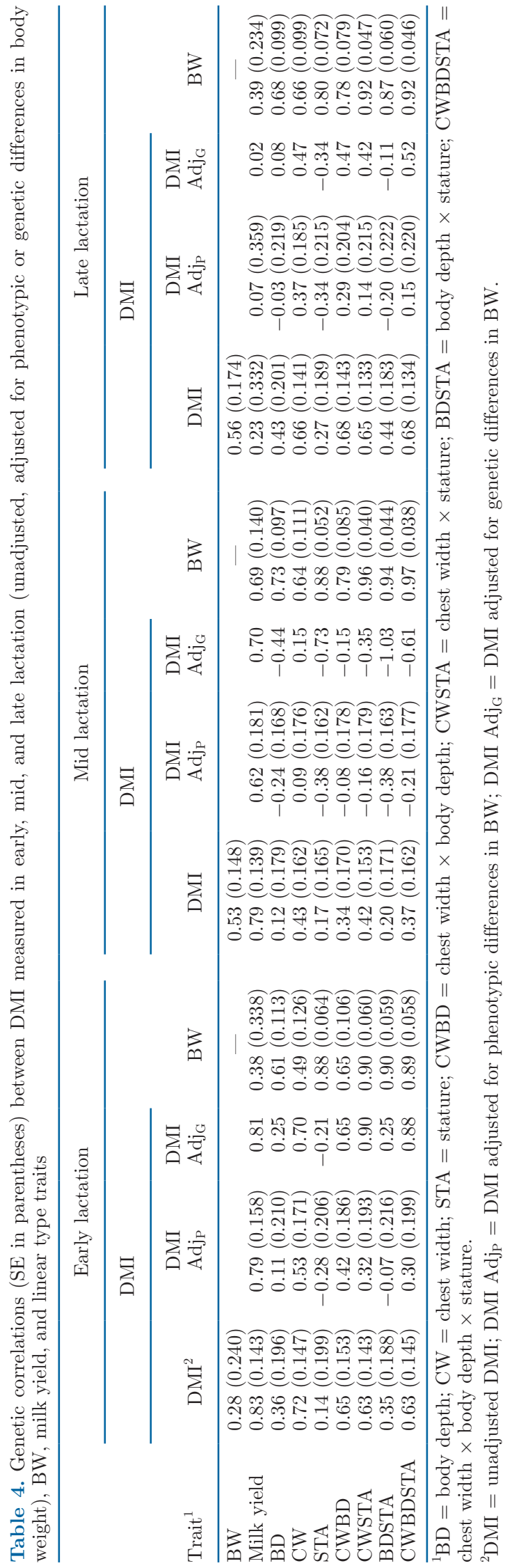

using these proxy traits. Therefore, the objectives of the present study were to estimate the genetic covariances between DMI and linear type traits, in particular after adjusting for differences in BW, and to validate a series of multitrait genetic evaluation models for DMI generated using such indicator traits. Should the linear type traits have some predictive ability for DMI in the validation population, EBV for DMI could be generated for the national population of Holstein-Friesian dairy cows.

\section{Genetic Variance Estimates}

The heritability estimates of DMI, BW, and milk yield across lactations were similar to those previously reported in dairy cows (Berry et al., 2003; Manafiazar et al., 2016; Manzanilla-Pech et al., 2016). No previous study has, to the best of our knowledge, reported variance components for DMI adjusted for phenotypic differences in BW. The effect on heritability of DMI from adjusting for phenotypic differences in BW was associated with a change in the coefficient of genetic variation of DMI, rather than a change in the coefficient of residual variation. The heritability estimates of the novel composite traits CWBD, CWSTA, BDSTA, and CWBDSTA, presented herein have not previously been reported, but are broadly in line with those associated with individual linear type traits in dairy cows (Veerkamp and Brotherstone, 1997; Manzanilla-Pech et al., 2016).

The heritability estimates of DMI and daily milk yield were lowest in early lactation; relative to DMI and daily milk yield measured in mid lactation, the lower heritability estimates of DMI and milk yield were associated with a $17 \%$ and $58 \%$ reduction in genetic variance, respectively, and a $39 \%$ and $24 \%$ increase in residual variance, respectively. The greater residual variance in early lactation was likely due to the changes in metabolic or physiological insults associated with early lactation in dairy cows, which were not accounted for in the statistical model due to a lack of available data on such metabolic and physiological changes.

\section{Indirect Selection for Feed Intake Across Lactation}

Genetic and phenotypic correlations between DMI and linear type traits have not been reported previously for grazing dairy cows. Nevertheless, they are similar to those reported by Veerkamp and Brotherstone (1997) and Manafiazar et al. (2016) in lactating Holstein and Holstein-Friesian dairy cows fed in confinement systems. While not previously reported, the phenotypic and genetic correlations between DMI and the novel 
Table 5. Pearson correlations and regression coefficients (SE in parentheses) for yield deviation of DMI on EBV for DMI; the EBVs were generated using combinations of DMI, BW, and linear type trait phenotypes

\begin{tabular}{|c|c|c|c|c|}
\hline \multirow[b]{2}{*}{$\begin{array}{l}\text { Phenotypes used to calculate } \\
\text { DMI EBV }\end{array}$} & \multicolumn{2}{|c|}{$\begin{array}{l}\text { All phenotypes of } 246 \\
\text { validation cows masked }\end{array}$} & \multicolumn{2}{|c|}{$\begin{array}{l}\text { DMI and linear type trait phenotypes } \\
\text { of } 246 \text { validation cows masked }\end{array}$} \\
\hline & $\begin{array}{l}\text { Correlation } \\
\text { coefficient }\end{array}$ & $\begin{array}{l}\text { Regression } \\
\text { coefficient }\end{array}$ & $\begin{array}{l}\text { Correlation } \\
\text { coefficient }\end{array}$ & $\begin{array}{l}\text { Regression } \\
\text { coefficient }\end{array}$ \\
\hline DMI & 0.144 & $0.63(0.103)$ & & \\
\hline DMI and BD & 0.140 & $0.58(0.099)$ & & \\
\hline DMI and CW & 0.148 & $0.61(0.097)$ & & \\
\hline DMI and CWSTA & 0.156 & $0.66(0.099)$ & & \\
\hline DMI and BDSTA & 0.148 & $0.63(0.101)$ & & \\
\hline DMI and CWBDSTA & 0.150 & $0.64(0.100)$ & & \\
\hline DMI and BW & 0.188 & $0.88(0.110)$ & 0.325 & $0.94(0.065)$ \\
\hline DMI, BD, and BW & 0.179 & $0.82(0.107)$ & 0.336 & $0.95(0.066)$ \\
\hline DMI, CW, and BW & 0.182 & $0.80(0.103)$ & 0.320 & $0.92(0.065)$ \\
\hline DMI, STA, and BW & 0.188 & $0.88(0.109)$ & 0.331 & $0.96(0.066)$ \\
\hline $\mathrm{CW}$ & 0.116 & $0.93(0.190)$ & & \\
\hline STA & 0.076 & $0.72(0.224)$ & & \\
\hline CWBD & 0.126 & $1.11(0.210)$ & & \\
\hline CWSTA & 0.127 & $0.78(0.147)$ & & \\
\hline BDSTA & 0.088 & $0.72(0.196)$ & & \\
\hline CWBDSTA & 0.117 & $0.78(0.159)$ & & \\
\hline BW & 0.128 & $0.53(0.097)$ & 0.337 & $1.11(0.074)$ \\
\hline $\mathrm{BD}$ and $\mathrm{BW}$ & 0.130 & $0.60(0.108)$ & 0.340 & $1.15(0.076)$ \\
\hline $\mathrm{CW}$ and $\mathrm{BW}$ & 0.160 & $0.73(0.107)$ & 0.351 & $1.18(0.075)$ \\
\hline STA and BW & 0.117 & $0.57(0.116)$ & 0.286 & $0.83(0.066)$ \\
\hline CWBD and BW & 0.145 & $0.65(0.106)$ & 0.345 & $1.17(0.076)$ \\
\hline CWSTA and BW & 0.146 & $0.67(0.108)$ & 0.346 & $1.20(0.078)$ \\
\hline BDSTA and BW & $0.040^{\mathrm{NS}}$ & $0.13(0.086)$ & 0.190 & $0.47(0.058)$ \\
\hline CWBDSTA and BW & 0.140 & $0.66(0.113)$ & 0.348 & $1.24(0.080)$ \\
\hline
\end{tabular}

composite traits were broadly in line with those of their component linear type traits in confined dairy cows (Manafiazar et al., 2016; Manzanilla-Pech et al., 2016). The genetic correlations suggest that between $8 \%(\mathrm{STA})$ and $39 \%(\mathrm{CW})$ of the genetic variance in DMI is explained by differences in genetic merit for the traditional linear type traits. Similarly, based on the genetic correlations, $15 \%$ (BDSTA) to $37 \%$ (CWSTA) of the genetic variance in DMI is explained by the difference in genetic merit for the novel composite traits. The strength of the genetic correlations between CW and DMI, and between CWSTA and DMI, suggests both traits reflect rumen volume more accurately than other linear type traits or novel composite traits. Assuming a traditional multitrait genetic evaluation with DMI as the goal trait and one linear type trait (here assumed to be CWSTA) in the selection index, a theoretical accuracy of selection for DMI of 0.60 could be achieved with 500 progeny linear score records with- out a requirement for DMI information on the progeny. The accuracy could never surpass 0.61 (i.e., the genetic correlation between DMI and CWSTA) in the absence of other information, either on DMI itself or other correlated traits.

While the genetic correlations between the linear type traits and DMI demonstrate their potential usefulness in predicting genetic merit for DMI within a multitrait genetic evaluation, the genetic correlations between the linear type traits, the novel composite traits, and BW were moderate to strong (0.47 to 0.86); other studies have reported genetic correlations ranging from 0.13 to 0.84 between the linear type traits used in the present study and BW in dairy cows (Veerkamp and Brotherstone, 1997; Berry et al., 2004; Manafiazar et al., 2016; Manzanilla-Pech et al., 2016). The strong genetic correlations between $\mathrm{BW}$ and the linear type traits, and between BW and the novel composite traits, reflect the accuracy with which linear type traits could 
predict genetic merit for $\mathrm{BW}$; it has previously been reported that linear type measurements could provide suitable estimates of the genetic merit of BW (Banos and Coffey, 2012). Nonetheless, advances in automation technology imply that the routine recording of BW may soon become a reality on many farms (Song et al., 2018). Such data, if captured, could be directly incorporated into a multitrait genetic evaluation for DMI. Given this, of particular interest in the present study was the marginal information content of linear type traits, especially the novel composite traits, over and above that already captured by BW. While adjusting for BW generally weakened the genetic correlations, some linear type traits were still moderately genetically correlated with DMI, even after adjusting DMI phenotypically or genetically for differences in BW. The strong positive genetic correlation between $\mathrm{CW}$ and DMI after adjusting for genetic differences in BW suggests that even when BW records are available, the inclusion of CW could improve the accuracy of predicting DMI; the strong genetic correlation between $\mathrm{CW}$ and DMI suggests that $\mathrm{CW}$ might be a suitable estimator of rumen volume. Assuming a traditional multitrait genetic evaluation with DMI as the goal trait, including progeny $\mathrm{CW}$ records in the selection index, in addition to progeny BW records, could increase the accuracy of selection for DMI by up to $17 \%$ compared with using only progeny BW records. Nonetheless, when EBV for DMI were generated with $\mathrm{CW}$, in combination with BW phenotypes from either the calibration population or from all animals, an improvement in predictive ability of DMI never actually materialized. In fact, based on the results from the genetic evaluations, neither the traditional linear type traits nor the novel composite traits were useful predictors of DMI when BW phenotypes were also available to predict DMI. Nevertheless, should neither BW nor DMI phenotypes be available, breeding values of similar accuracy to those estimated with DMI phenotypes of the calibration population could be estimated using either CWBD or CWSTA. As only 309 cows had both DMI and linear type trait phenotypes in the present study, 77 of which were in the validation population, there were insufficient records to generate accurate EBV for DMI using the linear type trait phenotypes of the validation population. Given that the genetic correlations between some of the linear type traits and DMI were similar to the genetic correlation between DMI and BW, it could be speculated that if linear type trait information was available for the entire validation population, then more accurate EBV for DMI could be generated from linear type trait phenotypes, as was the case when BW phenotypes of the validation population were used.

\section{Indirect Selection for Feed Intake in Different Stages of Lactation}

Both feed intake and milk production increase in early-lactating dairy cows, but the energy ingested is not sufficient to meet the total energy demands of the cow, resulting in negative energy balance (Beam and Butler, 1997; Berry et al., 2006). Therefore, the associations between the linear type traits and DMI were investigated within each stage of lactation, with the predictive ability of DMI in early lactation being of particular interest. The phenotypic and genetic correlation between BW and DMI were weakest in early lactation; implying 1 of 2 things: (1) in early lactation, energy sinks other than BW (e.g., milk production) are a greater drain on the energy available, or (2) other health conditions common in early lactation (Bradley and Green, 2005; LeBlanc et al., 2005; Dubuc et al., 2010) may cloud the association between body size, here represented by BW, and DMI. Although the genetic correlation between DMI and BW was weak in early lactation, with the exception $\mathrm{BD}$, STA, and BDSTA, the genetic correlations between DMI and the linear type traits were positive and strongest in early lactation, after adjusting for genetic differences in BW. This suggests that linear type traits may be suitable indicators of DMI in early lactation. The novel composite trait CWSTA explained $80 \%$ of the genetic variance in DMI in early lactation after differences in genetic merit for BW were accounted for; this was much greater than the $4 \%$ of the genetic variance of DMI explained by CWSTA across the entire lactation. This increase in the proportion of the genetic variance of DMI explained by linear type traits in early lactation, relative to in mid and late lactation, reflect the pasture-based nature of the Irish production system; because grass DM is lower in spring, compared with other seasons (McGilloway and Mayne, 1996), a greater rumen volume is required to ingest the same DMI and it is in early lactation where as high as possible DMI is desired by the cow to meet her energy requirements. Hence, a trait reflecting the rumen capacity of the cow could provide a useful prediction of the genetic propensity for feed intake in early lactation when feed intake is crucial.

\section{CONCLUSIONS}

The inclusion of feed intake in dairy cow breeding goals is currently restricted due to the resource requirements associated with the capture of individual cow feed intake data, particularly in a pasture-based environment. While the genetic correlations between DMI and linear type traits across lactation suggested 
linear type traits might be suitable proxy measures for DMI, the expected improvement in the prediction of DMI from the inclusion of information on linear type trait did not materialize. Nevertheless, a novel composite trait, representing rumen capacity, could provide a useful prediction of the genetic merit for feed intake in early lactation and therefore potentially generate breeding values for DMI in early lactation for a large population of dairy cows. As DMI in early lactation is often not sufficient to meet the total energy demands of the cow, EBVs for DMI could assist producers in selecting for cows with greater DMI in early lactation potentially negating the complications associated with negative energy balance.

\section{ACKNOWLEDGMENTS}

This publication has emanated from research supported in part by the Department of Agriculture, Food and the Marine (Dublin, Ireland) Research Stimulus Fund 17/S/235 (GreenBreed) as well as funding from a research grant from Science Foundation Ireland (Dublin, Ireland) and the Department of Agriculture, Food and Marine on behalf of the Government of Ireland under the Grant 16/RC/3835 (VistaMilk). The authors have not stated any conflicts of interest.

\section{REFERENCES}

Alawneh, J. I., M. A. Stevenson, N. B. Williamson, N. Lopez-Villalobos, and T. Otley. 2011. Automatic recording of daily walkover liveweight of dairy cattle at pasture in the first 100 days in milk. J. Dairy Sci. 94:4431-4440. https://doi.org/10.3168/jds.2010-4002.

Banos, G., and M. P. Coffey. 2012. Prediction of liveweight from linear conformation traits in dairy cattle. J. Dairy Sci. 95:2170-2175. https://doi.org/10.3168/jds.2011-4838.

Beam, S. W., and W. R. Butler. 1997. Energy balance and ovarian follicle development prior to the first ovulation postpartum in dairy cows receiving three levels of dietary fat. Biol. Reprod. 56:133-142. https://doi.org/10.1095/biolreprod56.1.133.

Berry, D. P., F. Buckley, P. Dillon, R. D. Evans, M. Rath, and R. F. Veerkamp. 2003. Genetic relationships among body condition score, body weight, milk yield, and fertility in dairy cows. J. Dairy Sci. 86:2193-2204. https://doi.org/10.3168/jds.S0022 -0302(03)73809-0.

Berry, D. P., F. Buckley, P. Dillon, R. D. Evans, and R. F. Veerkamp. 2004. Genetic relationships among linear type traits, milk yield, body weight, fertility and somatic cell count in primiparous dairy cows. Ir. J. Agric. Food Res. 43:161-176.

Berry, D. P., M. P. Coffey, J. E. Pryce, Y. de Haas, P. Løvendahl, N. Krattenmacher, J. J. Crowley, Z. Wang, D. Spurlock, K. Weigel, K. Macdonald, and R. F. Veerkamp. 2014. International genetic evaluations for feed intake in dairy cattle through the collation of data from multiple sources. J. Dairy Sci. 97:3894-3905. https://doi .org $/ 10.3168 /$ jds.2013-7548.

Berry, D. P., and J. J. Crowley. 2013. Cell Biology Symposium: Genetics of feed efficiency in dairy and beef cattle. J. Anim. Sci. 91:1594-1613. https://doi.org/10.2527/jas.2012-5862.

Berry, D. P., N. C. Friggens, M. Lucy, and J. R. Roche. 2016. Milk production and fertility in cattle. Annu. Rev. Anim. Biosci. 4:269-290. https://doi.org/10.1146/annurev-animal-021815-111406.
Berry, D. P., B. Horan, M. O'Donovan, F. Buckley, E. Kennedy, M. McEvoy, and P. Dillon. 2007. Genetics of grass dry matter intake, energy balance, and digestibility in grazing Irish dairy cows. J. Dairy Sci. 90:4835-4845. https://doi.org/10.3168/jds.2007-0116.

Berry, D. P., R. F. Veerkamp, and P. Dillon. 2006. Phenotypic profiles for body weight, body condition score, energy intake, and energy balance across different parities and concentrate feeding levels. Livest. Sci. 104:1-12. https://doi.org/10.1016/j.livsci.2006.02.012.

Bilal, G., R. I. Cue, and J. F. Hayes. 2016. Genetic and phenotypic associations of type traits and body condition score with dry matter intake, milk yield, and number of breedings in first lactation Canadian Holstein cows. Can. J. Anim. Sci. 96:434-447. https:// doi.org/10.1139/cjas-2015-0127.

Bradley, A., and M. Green. 2005. Use and interpretation of somatic cell count data in dairy cows. In Pract. 27:310-315. https://doi .org/10.1136/inpract.27.6.310.

Brotherstone, S. 1994. Genetic and phenotypic correlations between linear type traits and production traits in Holstein-Friesian dairy cattle. Anim. Sci. 59:183-187. https://doi.org/10.1017/ S0003356100007662.

Byrne, T. J., B. F. S. Santos, P. R. Amer, D. Martin-Collado, J. E. Pryce, and M. Axford. 2016. New breeding objectives and selection indices for the Australian dairy industry. J. Dairy Sci. 99:81468167. https://doi.org/10.3168/jds.2015-10747.

CDCB. 2020. Feed saved. Accessed Nov. 16, 2021. https://www.uscdcb .com/wp-content/uploads/2020/11/CDCB-Reference-Sheet-Feed -Saved-12_2020.pdf.

CDCB. 2021. Net merit 2021: Frequent questions. Accessed Nov. 16 2021. https://www.uscdcb.com/wp-content/uploads/2021/06/NM -2021-Frequent-Questions-06_07_2021.pdf.

Dillon, P., and G. Stakelum. 1989. Herbage and dosed alkanes as a grass measurement technique for dairy cows. Isr. J. Agric. Res. 28:104. (Abstr.)

Dubuc, J., T. F. Duffield, K. E. Leslie, J. S. Walton, and S. J. LeBlanc. 2010. Risk factors for postpartum uterine diseases in dairy cows. J Dairy Sci. 93:5764-5771. https://doi.org/10.3168/jds.2010-3429.

García-Ruiz, A., J. B. Cole, P. M. VanRaden, G. R. Wiggans, F. J. Ruiz-López, and C. P. Van Tassell. 2016. Changes in genetic selection differentials and generation intervals in US Holstein dairy cattle as a result of genomic selection. Proc. Natl. Acad. Sci. USA 113:E3995-E4004. https://doi.org/10.1073/pnas.1519061113.

Gill, M., A. J. Rook, and L. R. S. Thiago. 1988. Factors affecting the voluntary intake of roughages by the dairy cow. Pages $262-279$ in Nutrition and Lactation in the Dairy Cow. P. C. Garnsworthy, ed. Butterworths.

Gilmour, A. R., B. J. Gogel, B. R. Cullis, R. Thompson, D. Butler, M. Cherry, D. Collins, G. Dutkowski, S. A. Harding, and K. Haskard. 2008. ASReml user guide release 3.0. VSN International Ltd.

Halachmi, I., Y. Ben Meir, J. Miron, and E. Maltz. 2016. Feeding behavior improves prediction of dairy cow voluntary feed intake but cannot serve as the sole indicator. Animal 10:1501-1506. https:// doi.org/10.1017/S1751731115001809.

Halachmi, I., Y. Edan, U. Moallem, and E. Maltz. 2004. Predicting feed intake of the individual dairy cow. J. Dairy Sci. 87:2254-2267. https://doi.org/10.3168/jds.S0022-0302(04)70046-6.

Hurley, A. M., N. López-Villalobos, S. McParland, E. Lewis, E. Kennedy, M. O'Donovan, J. L. Burke, and D. P. Berry. 2017. Genetics of alternative definitions of feed efficiency in grazing lactating dairy cows. J. Dairy Sci. 100:5501-5514. https://doi.org/10.3168/ jds.2016-12314.

Lahart, B., S. McParland, E. Kennedy, T. M. Boland, T. Condon, M. Williams, N. Galvin, B. McCarthy, and F. Buckley. 2019. Predicting the dry matter intake of grazing dairy cows using infrared reflectance spectroscopy analysis. J. Dairy Sci. 102:8907-8918. https: //doi.org/10.3168/jds.2019-16363.

LeBlanc, S. J., K. E. Leslie, and T. F. Duffield. 2005. Metabolic predictors of displaced abomasum in dairy cattle. J. Dairy Sci. 88:159-170. https://doi.org/10.3168/jds.S0022-0302(05)72674-6.

Manafiazar, G., L. Goonewardene, F. Miglior, D. H. Crews Jr., J. A. Basarab, E. Okine, and Z. Wang. 2016. Genetic and phenotypic correlations among feed efficiency, production and selected confor- 
mation traits in dairy cows. Animal 10:381-389. https://doi.org/ 10.1017/S1751731115002281.

Manzanilla-Pech, C. I. V., R. F. Veerkamp, R. J. Tempelman, M. L. van Pelt, K. A. Weigel, M. VandeHaar, T. J. Lawlor, D. M. Spurlock, L. E. Armentano, C. R. Staples, M. Hanigan, and Y. de Haas. 2016. Genetic parameters between feed-intake-related traits and conformation in 2 separate dairy populations - the Netherlands and United States. J. Dairy Sci. 99:443-457. https://doi.org/10 $.3168 /$ jds.2015-9727.

Mayes, R. W., C. S. Lamb, and P. M. Colgrove. 1986. The use of dosed and herbage n-alkanes as markers for the determination of herbage intake. J. Agric. Sci. 107:161-170. https://doi.org/10.1017/ S0021859600066910.

McGilloway, D. A., and C. S. Mayne. 1996. Importance of grass availability for the high genetic merit dairy cow. Pages 135-169 in Recent Advances in Animal Nutrition. P. C. Garnsworthy, J. Wiseman, and W. Haresign, ed. Nottingham University Press.

McParland, S., E. Lewis, E. Kennedy, S. G. Moore, B. McCarthy, M. O'Donovan, S. T. Butler, J. E. Pryce, and D. P. Berry. 2014 Mid-infrared spectrometry of milk as a predictor of energy intake and efficiency in lactating dairy cows. J. Dairy Sci. 97:5863-5871. https://doi.org/10.3168/jds.2014-8214.

Pryce, J. E., O. Gonzalez-Recio, G. Nieuwhof, W. J. Wales, M. P. Coffey, B. J. Hayes, and M. E. Goddard. 2015. Hot topic: Definition and implementation of a breeding value for feed efficiency in dairy cows. J. Dairy Sci. 98:7340-7350. https://doi.org/10.3168/ jds.2015-9621.

Pryce, J. E., W. D. Wales, Y. De Haas, R. F. Veerkamp, and B. J. Hayes. 2014. Genomic selection for feed efficiency in dairy cattle. Animal 8:1-10. https://doi.org/10.1017/S1751731113001687.

Song, X., E. A. M. Bokkers, P. P. J. van der Tol, P. G. Koerkamp, and S. Van Mourik. 2018. Automated body weight prediction of dairy cows using 3-dimensional vision. J. Dairy Sci. 101:4448-4459. https://doi.org/10.3168/jds.2017-13094.
Strandén, I., and M. Lidauer. 1999. Solving large mixed linear models using preconditioned conjugate gradient iteration. J. Dairy Sci. 82:2779-2787. https://doi.org/10.3168/jds.S0022-0302(99)75535 -9 .

Toshniwal, J. K., C. D. Dechow, B. G. Cassell, J. A. D. R. N. Appuhamy, and G. A. Varga. 2008. Heritability of electronically recorded daily body weight and correlations with yield, dry matter intake, and body condition score. J. Dairy Sci. 91:3201-3210. https://doi.org/10.3168/jds.2007-0627.

Tran, H., P. Salgado, E. Tillard, P. Dardenne, X. T. Nguyen, and P. Lecomte. 2010. "Global" and "local" predictions of dairy diet nutritional quality using near infrared reflectance spectroscopy. J. Dairy Sci. 93:4961-4975. https://doi.org/10.3168/jds.2008-1893.

Veerkamp, R. F., and S. Brotherstone. 1997. Genetic correlations between linear type traits, food intake, live weight and condition score in Holstein Friesian dairy cattle. Anim. Sci. 64:385-392. https://doi.org/10.1017/S1357729800015976.

Wallén, S. E., E. Prestløkken, T. H. E. Meuwissen, S. McParland, and D. P. Berry. 2018. Milk mid-infrared spectral data as a tool to predict feed intake in lactating Norwegian Red dairy cows. J. Dairy Sci. 101:6232-6243. https://doi.org/10.3168/jds.2017-13874. Wherry, R. J. 1984. Composite and part correlation. Pages 34-44 in Contributions to Correlation Analysis. Academic Press Inc.

\section{ORCIDS}

M. Williams (ํ) https://orcid.org/0000-0001-7399-370X

C. P. Murphy @ https://orcid.org/0000-0002-6064-2211

R. D. Sleator ๑ https://orcid.org/0000-0001-5846-3938

S. C. Ring ๑ https://orcid.org/0000-0001-7495-4286

D. P. Berry @ https://orcid.org/0000-0003-4349-1447 